\title{
Purificação de exo-poligalacturonase microbiana por diferentes técnicas
}

\author{
Purification of microbial exo-polylaacturonase by different techniques \\ Purificación de exo-poligalacturonasa microbiana mediante diferentes técnicas
}

Recebido: 25/11/2021 | Revisado: 30/11/2021 | Aceito: 01/12/2021 | Publicado: 12/12/2021

\author{
Rafaela Nery de Melo \\ ORCID: https://orcid.org/0000-0002-1641-5994 \\ Universidade Regional Integrada do Alto Uruguai e das Missões, Brasil \\ E-mail: rafinha.nm@outlook.com \\ Lucas Henrique do Nascimento \\ ORCID: https://orcid.org/0000-0002-5223-2896 \\ Universidade Regional Integrada do Alto Uruguai e das Missões, Brasil \\ E-mail: lucashenryque.nascimento@gmail.com \\ Laís Thomazoni \\ ORCID: https://orcid.org/0000-0002-4215-5997 \\ Universidade Regional Integrada do Alto Uruguai e das Missões, Brasil \\ E-mail: lais.thomazoni@hotmail.com \\ Rosicler Colet \\ ORCID: https://orcid.org/0000-0001-8589-0804 \\ Universidade Regional Integrada do Alto Uruguai e das Missões, Brasil \\ E-mail: rosicler.colet@yahoo.com.br \\ Ilizandra Aparecida Fernandes \\ ORCID: https://orcid.org/0000-0002-9546-1971 \\ Universidade Regional Integrada do Alto Uruguai e das Missões, Brasil \\ E-mail: ilizandrafernandes@yahoo.com.br \\ Jamile Zeni \\ ORCID: https://orcid.org/0000-0002-0529-2212 \\ Universidade Regional Integrada do Alto Uruguai e das Missões, Brasil \\ E-mail: jamilezeni@uricer.edu.br \\ Rogério Marcos Dallago \\ ORCID: https://orcid.org/0000-0001-7366-5562 \\ Universidade Regional Integrada do Alto Uruguai e das Missões, Brasil \\ E-mail: dallago@uricer.edu.br \\ Eunice Valduga \\ ORCID: https://orcid.org/0000-0002-2553-0740 \\ Universidade Regional Integrada do Alto Uruguai e das Missões, Brasil \\ E-mail: veunice@uricer.edu.br
}

\begin{abstract}
Resumo
A demanda por processos de purificação de enzimas e proteínas, vem aumentando principalmente pela busca por parte das indústrias por produtos com elevado grau de pureza. A precipitação com polímeros não-iônicos, solventes e sais podem ser aplicados na purificação de enzimas, como a poligalacturonase, usada principalmente na produção de vinhos, sucos, alimentos processados como alimentos infantis, não acarretando prejuízos no rendimento. Neste contexto o objetivo do presente trabalho foi avaliar a eficiência de diferentes técnicas de concentração (prépurificação) enzimática. A precipitação com solventes acetona e etanol foi realizada nas concentrações de 1,2 e $3 \mathrm{~V}$, para o sulfato de amônio foram utilizadas concentrações de $0-80 \%$, com intervalos de $20 \%$. De acordo com os resultados da purificação parcial da poligalacturonase (PG), observou-se que as maiores recuperações da enzima foram obtidas em concentração de solvente de $3 \mathrm{~V}$ para etanol e $2 \mathrm{~V}$ para a acetona com valores de $47,05 \%$ e $42,85 \%$ respectivamente.
\end{abstract}

Palavras-chave: Poligalacturonase; Solventes; Concentração.

\begin{abstract}
The demand for enzyme and protein purification processes has been increasing, mainly due to the search on the part of industries for products with a high degree of purity. The transformation with non-ionic polymers, solvents and salts may be necessary in the purification of enzymes, such as polygalacturonase, used mainly in the production of wines, juices, processed foods such as infant foods, without resulting in yield losses. In this context, the objective of the present work was to evaluate the efficiency of different techniques of enzymatic concentration (pre-purification).
\end{abstract}


Reconstruction with acetone and ethanol solvents was performed in tools of 1,2 and $3 \mathrm{~V}$, for ammonium sulphate were used from $0-80 \%$, with intervals of $20 \%$. According to the results of the partial purification of polygalacturonase (PG), it was observed that the highest enzyme recoveries were added at a solvent concentration of $3 \mathrm{~V}$ for ethanol and $2 \mathrm{~V}$ for acetone with values of $47,05 \%$ and $42,85 \%$ respectively.

Keywords: Polygalacturonase; Solvents; Concentration.

\section{Resumen}

La demanda de procesos de depuración de enzimas y proteínas ha ido en aumento, principalmente debido a la búsqueda por parte de las industrias de productos con un alto grado de pureza. La transformación con polímeros no iónicos, disolventes y sales puede ser necesaria en la depuración de enzimas, como la poligalacturonasa, utilizadas principalmente en la elaboración de vinos, jugos, alimentos procesados como alimentos infantiles, sin que se produzcan pérdidas de rendimiento. En este contexto, el objetivo del presente trabajo fue evaluar la eficiencia de diferentes técnicas de concentración enzimática (prepurificación). La reconstrucción con solventes de acetona y etanol se realizó en herramientas de 1,2 y $3 \mathrm{~V}$, para el sulfato de amonio se utilizó de $0-80 \%$, con intervalos de $20 \%$. De acuerdo con los resultados de la purificación parcial de poligalacturonasa (PG), se observó que las mayores recuperaciones de enzimas se agregaron a una concentración de solvente de $3 \mathrm{~V}$ para etanol y $2 \mathrm{~V}$ para acetona con valores de $47,05 \%$ y $42,85 \%$ respectivamente.

Palabras clave: Poligalacturonasa; Solventes; Concentración.

\section{Introdução}

Enzimas pécticas (pectinases) são capazes de degradar a pectina, que é um polissacarídeo presente na parede celular de plantas, sendo constituído principalmente de polímeros de ácido galacturônico, ramnose, arabinose e galactose e a sua principal característica é conferir consistência e rigidez ao fruto e à planta. Assim, as pectinases apresentam benefícios industriais na extração e clarificação de sucos, maceração de vegetais e frutas, na extração de óleos e na indústria de papel e celulose. As poligalacturonases (PG) catalisam a hidrólise de ligação $\alpha-1,4$ entre resíduos de ácido galacturônico não estereficados. Sua ação pode ocorrer internamente na cadeia principal (endo-PG), liberando oligômeros, ou na extremidade não redutora (exo-PG), liberando monômeros (Pagnonceli, 2018).

Estas enzimas podem ser produzidas por via biotecnológica (uso de microrganismos), porém o processo é influenciado pelas condições de cultivo ( $\mathrm{pH}$, temperatura, aeração, velocidade de agitação e tempo de incubação) e a composição do meio de crescimento (principalmente carbono e fontes de nitrogênio). Por conseguinte, estes têm de ser especificados individualmente para cada linhagem de interesse (John et al., 2020).

Vários gêneros de microrganismos, tais como Bacillus, Erwinia, Kluyveromyces, Aspergillus, Rhizopus, Trichoderma, Pseudomonas, Penicillium e Fusarium são conhecidos como bons produtores de pectinases (Zeni et al., 2011).

$\mathrm{O}$ emprego de Aspergillus niger em processos fermentativos possui vantagens pela capacidade deste em se desenvolver em meios sólidos e líquidos, podendo fermentar uma grande variedade de matérias-primas de baixo custo e possuir esporulação rápida (Gautam et al., 2011; Muruci, 2012). Ele atua como um recurso excelente, pois é geralmente considerado seguro (GRAS) e também seus metabólitos são atóxicos por natureza, obtendo bons benefícios econômicos (Huang et al., 2019).

A intrínseca composição do meio fermentativo (matérias primas precursoras de carbono e nitrogênio, aditivos, cofatores e estimulantes, entre outros) necessária para um bom crescimento microbiano também contribui para a complexidade composicional dos extratos enzimáticos obtidos, os quais normalmente devem ser submetidos a processos de purificação, seja para remoção de interferentes ou pré-concentração da enzima, para melhor o desempenho catalitico da enzima produzida.

Neste aspecto a demanda por processos de purificação de biomoléculas, especialmente proteínas, que sejam eficientes, rápidos e confiáveis vem crescendo nos últimos anos, especialmente na área de biotecnologia e bioprocessos (Trentini, 2014). Alguns exemplos de métodos de purificação usados nas indústrias incluem a precipitação com sulfato de amônio ou com solventes (etanol/acetona), a diálise e a ultrafiltração (Ahmned et al., 2016). 
Destes, se considerarmos a simplicidade e os custos operacionais, aliada a trajetória investigativa, uma vez que foi um dos primeiros métodos empregados em escala industrial, destaca-se a precipitação (Wingfield, 2001; Burgess, 2009; Razzaq et al., 2019).

A precipitação de proteínas com sais e solventes orgânicos é feita com o objetivo de concentrar e remover contaminantes não proteicos. De maneira geral, a solubilidade das enzimas depende da distribuição de grupos ionizáveis, zonas hidrofóbicas e hidrofílicas na superfície da molécula que são responsáveis por interações polares com o solvente aquoso, interações iônicas com os sais, e pela repulsão eletrostática entre as moléculas. O controle desses fatores permite maximizar a separação e recuperação de uma enzima (Damodaran et al., 2018).

$\mathrm{O}$ sulfato de amônio $\left(\left(\mathrm{NH}_{4}\right)_{2} \mathrm{SO}_{4}\right)$ é um dos sais mais utilizados para precipitar proteínas devido a sua elevada solubilidade, baixo custo, baixa toxicidade e praticidade (Prestes \& Adaime, 2011). No método de precipitação com sulfato de amônio, concentrações de sais mais elevadas são empregadas para alterar a solubilidade e, portanto, um fácil fracionamento e separação das enzimas pectinase pode ser alcançado (Ahmed et al., 2016). Nessa técnica, é muito importante que o sal não provoque perturbações estruturais na molécula polipeptídica que se pretende purificar, caso contrário, poderá acarretar a redução parcial ou mesmo completa, da atividade que ela desempenha (Santos, 2020).

O método de precipitação com etanol é feito quando as impurezas que são solúveis em álcool precisam ser removidas e, assim, uma forma purificada de pectinase pode ser obtida (Tackci \& Turkmen, 2016).

O emprego da acetona em metodologias experimentais destinada à purificação de proteínas assume uma versatilidade ainda maior, quando comparada ao álcool etílico, pois além de sua utilização como agente precipitante, constata-se também o seu emprego como solvente desengordurante, bem como extrator de metabólitos de menor solubilidade (Ktari et al., 2012).

Sabendo da grande visibilidade do uso de poligalacturonase no setor industrial, é relevante a realização de estudos e caracterização dos processos que envolvem a produção desta enzima. Em decorrência disto, vários estudos foram conduzidos com o intuito de purificar e caracterizar as poligalacturonases fúngicas obtidas de diferentes microrganismos (Abdulaal \& Almulaiky, 2020; Nawaz et al., 2021).

Buscando contribuir com este tema, este trabalho teve como objetivo avaliar o processo de pré-purificação da enzima poligalacturonase utilizando diferentes solventes (álcool etílico e acetona) e sal (sulfato de amônio), a fim de verificar qual o melhor agente precipitante, e melhor concentração a ser adicionada.

\section{Metodologia}

\subsection{Bioprodução de Exo-Poligalacturonase}

A exo-poligalacturonase empregada neste estudo foi bioproduzida a partir de cultivo submerso utilizando Aspergillus niger ATCC 9642 (Figura 1a), o qual foi cultivado em PDA durante 7 dias a $30^{\circ} \mathrm{C}$. Em seguida, a coleta dos esporos foi realizada adicionando-se $20 \mathrm{~mL}$ de solução aquosa de Tween $80(0,1 \% \mathrm{v} / \mathrm{v})$, e pérolas de vidro estéreis adicionadas ao frasco, para uma melhor remoção dos esporos. A suspensão resultante foi armazenada a $4^{\circ} \mathrm{C}$ até sua utilização, o que não ultrapassava um tempo máximo de 15 dias. Para contagem dos esporos, $1 \mathrm{~mL}$ da suspensão, retirada assepticamente, foi diluído de 10 a $10^{3}$ vezes em solução aquosa estéril de Tween $80(0,1 \%$ v/v). A suspensão resultante foi transferida para uma câmara de Neubauer (Inlab) para contagem dos esporos (Freire, 1996).

O meio de bioprodução da exo-poligalacturonase (Figura $1 \mathrm{~b}$ ) utilizado constituía-se de $32 \mathrm{~g} / \mathrm{L}$ de pectina cítrica, $2 \mathrm{~g} / \mathrm{L}$ de $\mathrm{L}$-asparagina, $0,06 \mathrm{~g} / \mathrm{L}$ de fosfato de potássio, $1,0 \mathrm{~g} / \mathrm{L}$ de sulfato de ferro, agitação $180 \mathrm{rpm}, 5 \times 10^{6}$ esporos $/ \mathrm{mL}, 25^{\circ} \mathrm{C}, \mathrm{pH}$ inicial de 4,0 e 27 h de fermentação (Gomes et al., 2010). 
Figura 1. Aspecto visual do fungo Aspergillus niger ATCC 9642 (a) e do meio de bioprodução (b).

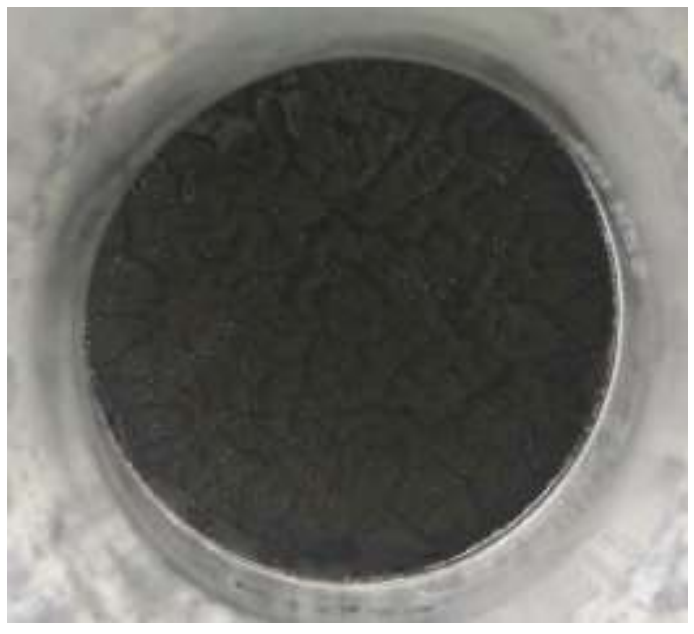

(a)

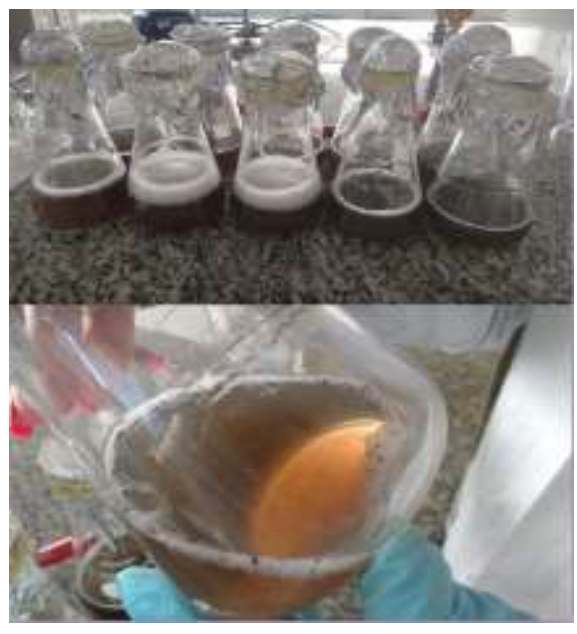

(b)

Fonte: Autores.

\subsection{Precipitação com acetona}

A precipitação com acetona foi realizada adicionando-se ao extrato enzimático uma proporção de acetona de 1:1, 1:2 e $1: 3(\mathrm{v} / \mathrm{v})$, a $-15^{\circ} \mathrm{C}$. A seguir o material foi centrifugado $(10.000 \mathrm{rpm})$ por $15 \mathrm{~min}$ a $5^{\circ} \mathrm{C}$. O precipitado formado foi ressuspendido em $10 \mathrm{~mL}$ de tampão acetato de sódio $\mathrm{pH}$ 5,5, para posterior medida de atividade e teor de proteína, conforme apresentado na Figura 2.

Figura 2. Fluxograma das etapas de precipitação com acetona.

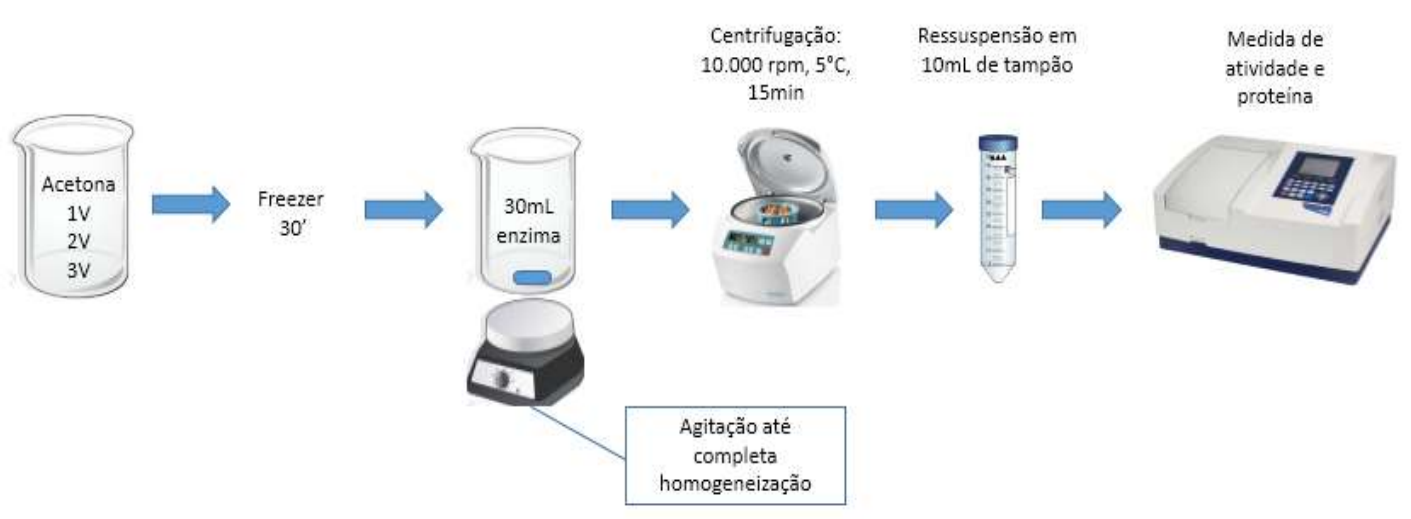

Fonte: Autores.

\subsection{Precipitação com etanol}

Realizou-se o procedimento como citado no item anterior, porém ao invés da acetona, utilizou-se o etanol, sendo $1 \mathrm{~V}$, $2 \mathrm{~V}$ e $3 \mathrm{~V}$, o que significa $10 \mathrm{~mL}$ de extrato: $30 \mathrm{~mL}$ de etanol, $10 \mathrm{~mL}$ de extrato: $60 \mathrm{~mL}$ de etanol e $10 \mathrm{~mL}$ de extrato: $90 \mathrm{~mL}$ de etanol, respectivamente.

\subsection{Precipitação com sulfato de amônio}

$\mathrm{Na}$ precipitação com sulfato de amônio, os ensaios foram conduzidos com $30 \mathrm{~mL}$ de extrato bruto, o qual foram adicionados, de forma independente, diferentes massas do agente precipitante, sendo 4,236g; 8,472g; 12,708g e 16,944g, os 
quais correspondem a percentuais de 20,40,60 e 80\%, respectivamente. O mesmo foi adicionado lentamente sob agitação constante, e deixado a mistura na geladeira durante $12 \mathrm{~h}$. Decorrido este tempo, levou-se para centrífuga $(10.000 \mathrm{rpm})$ a $5^{\circ} \mathrm{C}$ por $15 \mathrm{~min}$. O precipitado recuperado foi ressuspendido em $10 \mathrm{~mL}$ de tampão acetato de sódio $\mathrm{pH}$ 5,5, para posterior medida de atividade e teor de proteína. As etapas desta precipitação são apresentadas na Figura 3 em forma de fluxograma.

Figura 3. Fluxograma das etapas de precipitação com sulfato de amônio.

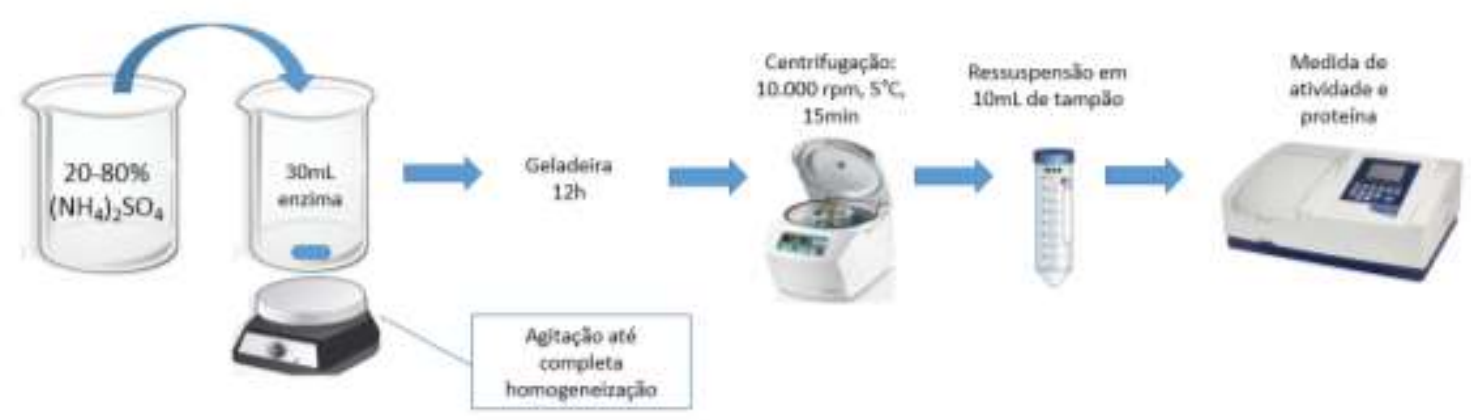

Fonte: Autores.

\subsection{Atividade enzimática da exo-poligalacturonase}

A atividade enzimática da exo-poligalacturonase (exo-PG) foi determinada pela medida da liberação de grupos redutores através do método do ácido dinitrosalisílico (DNS), proposto inicialmente por Miller (1956). Inicialmente, preparouse $1 \mathrm{~mL}$ de substrato (solução $0,5 \%$ de pectina cítrica (Sigma) em tampão acetato de sódio $\mathrm{pH}$ 5,5) e incubou-se a $40^{\circ} \mathrm{C}$ por 15 min para estabilização de temperatura. A seguir, $0,5 \mathrm{~mL}$ de extrato enzimático foram adicionados ao substrato e a reação incubada a $40^{\circ} \mathrm{C}$ por um período de reação de 6 min. Após a adição de $1 \mathrm{~mL}$ de solução de DNS, a mistura foi mantida em ebulição por 8 min para formação de cor, resfriada em banho de gelo e adicionados $8 \mathrm{~mL}$ de solução $50 \mathrm{mM}$ de tartarato duplo de sódio-potássio para estabilização de cor. A absorbância foi medida em espectrofotômetro (Beckman Coutler, modelo DU640), a $540 \mathrm{~nm}$, contra o branco. Uma unidade de atividade de exo-PG foi definida como a quantidade de enzima que libera 1 mol de ácido d-galacturônico por minuto de reação $(\mathrm{U}=\mathrm{mol} / \mathrm{min})$. A atividade de exo-PG foi expressa em unidades de atividade por $\mathrm{mL}(\mathrm{U} / \mathrm{mL})$.

\subsection{Proteínas totais}

Foram separadas alíquotas de cada ensaio para determinar o valor de proteína total da enzima citada anteriormente. As concentrações de proteínas foram medidas espectrofotometricamente a 595nm através do método de Bradford (1976), usando albumina bovina (BSA, Merck, Alemanha) como padrão e reagente de Bradford (Comassie Blue G-250).

\subsection{Atividade enzimática específica}

As proteínas presentes no extrato enzimático foram quantificadas para determinar a atividade enzimática específica, a qual representa o índice gerado pela relação entre a atividade enzimática $(\mathrm{U} / \mathrm{mL})$ e o valor de proteínas totais $(\mathrm{mg} / \mathrm{mL}) \mathrm{da}$ mesma amostra, ou seja, a atividade enzimática (U) por mg de proteínas (U/mg), conforme apresentado na Equação 1:

$$
\text { U específico }=\frac{U \text { enzimático }(U / m L)}{\text { proteínas totais }(\mathrm{mg} / \mathrm{mL})}
$$




\subsection{Recuperação ou rendimento de enzima (RP)}

A recuperação das enzimas foi calculada pela Equação 2 (Porto et al., 2008).

$$
P=\frac{A_{\text {enzima purificada }} \times V_{\text {purificado }}}{A_{\text {extrato bruto }} \times V_{\text {inicial }}}
$$

Sendo:

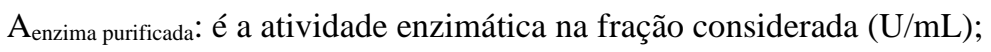

$A_{\text {extrato bruto: }}$ é a atividade enzimática na alimentação $(\mathrm{U} / \mathrm{mL})$;

$\mathrm{V}_{\text {inicial: }}$ é o volume inicial do extrato adicionado em $\mathrm{mL}$.

\section{Resultados e Discussões}

O extrato enzimático bruto obtido da produção via fermentação utilizando Aspergillus niger ATCC 9642 apresentou atividade enzimática de exo-PG de 3,66 U/mL, teor de proteína $0,03 \mathrm{mg} / \mathrm{mL}$ e atividade específica de $115 \mathrm{U} / \mathrm{mg}$.

A Figura 4 apresenta os resultados da recuperação da PG quando precipitada em acetona e etanol, onde observa-se que conforme aumentava-se o volume de etanol adicionado, aumenta-se a porcentagem de recuperação da enzima, sendo necessário três volumes de etanol para obter $47,05 \%$ de recuperação da enzima. Já para a acetona, a melhor recuperação enzimática foi na concentração de dois volumes com uma recuperação de $42,85 \%$.

Figura 4. Porcentagem de recuperação da enzima precipitada com acetona e etanol.

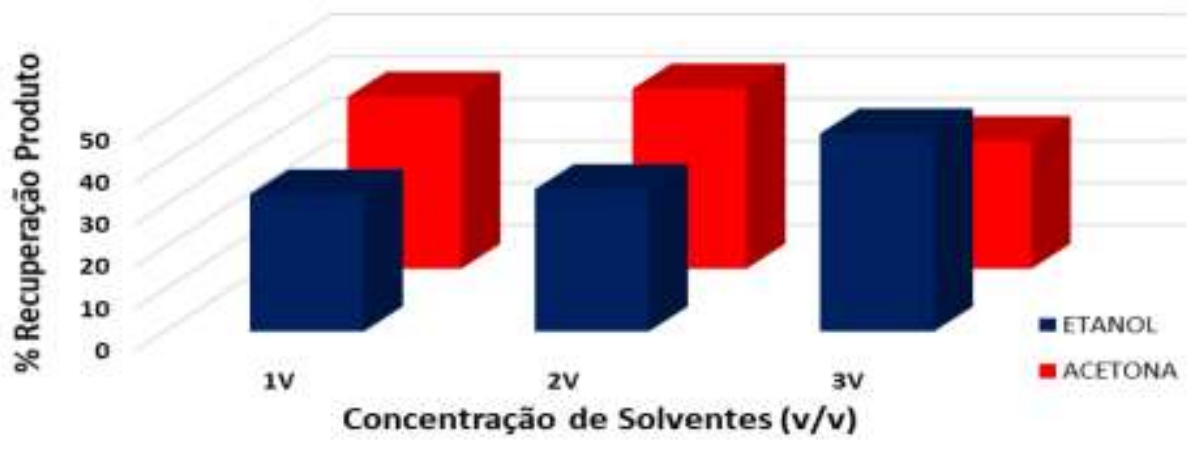

Fonte: Autores.

Atualmente há uma grande utilização de solventes orgânicos, principalmente o metanol, o etanol e a acetona (Biazus et al., 2010). Na precipitação pela adição de solventes orgânicos, o acréscimo de solvente diminui a constante dielétrica da solução, reduzindo o poder de solvatação da água sobre as proteínas hidrofílicas carregadas e, consequentemente, na diminuição de sua solubilidade, acarretando em sua precipitação (Tacin et al., 2019).

Esta diminuição da constante dielétrica da solução também contribui com o aumento da atração entre as moléculas de proteína, conduzindo a formação de agregados, que ao atingirem proporções macroscópicas tendem a precipitar (Cortez \& Pessoa, 1999; Yoshikawa et al., 2012).

A vantagem da precipitação com acetona e com etanol é que o solvente pode ser rapidamente evaporado do sedimento à vácuo sem a necessidade de processos posteriores para remoção do precipitante (Pereira et al., 2010).

Concentrações moderadas ( $10 \%$ a $40 \%$, v/v) de etanol tem sido utilizado como um dos métodos mais eficazes para fraccionar proteínas de plasma em vários produtos terapêuticos funcionais. Em baixas temperaturas, os solventes orgânicos 
diminuem a solubilidade de proteínas no estado nativo. No entanto, em contraste com os sais de salting-out, álcoois e outros solventes orgânicos são desestabilizadores da proteína e podem desnaturar proteínas em concentrações elevadas ou a temperaturas elevadas devido à suas interações favoráveis com grupos hidrofóbicos (Yoshikawa et al., 2012).

No estudo feito por Trentini (2014), os resultados para exo-PG na fase precipitada foram baixas, sugerindo que a enzima não foi precipitada pelo solvente. Por outro lado, a enzima foi detectada no sobrenadante, e a atividade específica nesta fase aumentou, mostrando a purificação de exo-PG por precipitação seletiva de proteínas com etanol. Um Fator de Purificação (FP) ótimo de exo-PG pode ser observado a 50\% de etanol. Se as taxas e a concentração de etanol forem muito altas, alguns dos inibidores e proteínas podem ser arrastados com a enzima, o que pode diminuir o fator de purificação e rendimento de atividade. Além disso, o excesso de etanol pode causar desnaturação enzimática.

No estudo feito por Santos Junior et al. (2017) utilizando acetona e metanol (1, 2 e 3V) como agentes precipitantes, verificou-se que com o aumento da concentração no gradiente agente precipitante/proteína, houve uma maior precipitação de proteínas.

A Figura 5 apresenta os resultados da precipitação com sulfato de amônio, onde é possível observar uma tendência inversa ao dos solventes orgânicos, com uma diminuição da recuperação percentual de enzima com o aumento da concentração do sal.

Figura 5. Recuperação da enzima quando precipitada com sulfato de amônio.

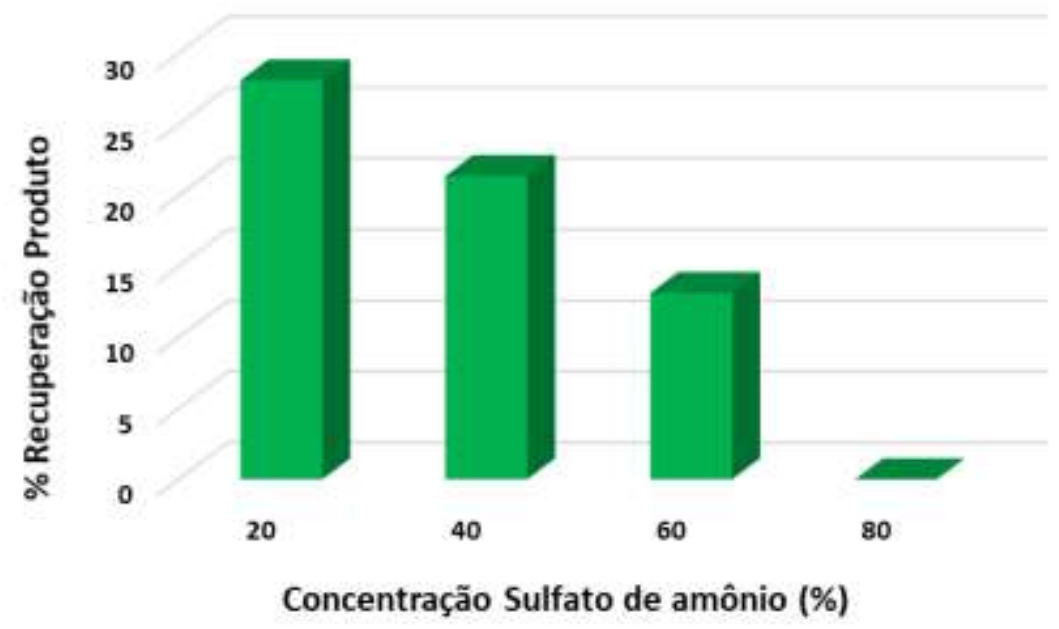

Fonte: Autores.

Dentre as técnicas de precipitação a utilização de sulfato de amônio é a mais utilizada devido à precipitação da maioria das proteínas ocorrer em uma molaridade alta, não promover o aquecimento da solução (em comparação com a utilização de solventes como etanol), apresentar uma densidade que não interfere na sedimentação da maioria das proteínas e promover o efeito de concentração das proteínas (Kanwar et al., 2006).

A adição de sais como sulfato de amônio e cloreto de sódio em altas concentrações, de 1,5 a 3,0M, reduz a disponibilidade de água devido à hidratação preferencial dos íons e evita a solvatação da enzima (Bom et al., 2008). Purwanto (2016) observou a redução da atividade específica e da recuperação quando adicionada a etapa de fracionamento com sulfato de amônio (60\%) antes da cromatografia de troca iônica. Salehi et al. (2017) usaram diferentes concentrações de sulfato de amônio (20\%-80\%) para precipitação de proteases de Withania coagulan. sendo que o maior valor de atividade coagulante e proteolítica foi encontrado quando usado com concentrações de 20-50\% de sulfato de amônio. 
Santos et al. (2014) obtiveram os melhores resultados para a concentração da enzima tirosinase em intervalos de saturação de 40-60\%, sendo a recuperação da atividade total de 85,9\%. Amin et al. (2021) produziram Exo-PG a partir de Penicillium fellutanum e ao utilizarem a técnica de precipitação com sulfato de amônio, perceberam que a enzima exibiu um aumento de sua atividade até atingir $75 \%$ de saturação.

Ao comparar a precipitação com sulfato de amônio e com etanol para obtenção de proteínas de batata, Waglay et al. (2014) relatam que com o aumento na concentração de etanol até $20 \%$ foi possível obter $55,2 \%$ de recuperação e purificação de 3,79. O aumento da concentração de etanol para 30\% reduziu a recuperação e purificação para 15\% e 1,19, respectivamente. Foi observado o aumento na recuperação de proteína (70-98\%) em função da concentração de sulfato de amônio (40-60\%), embora tenha sido observado pequenas alterações no fator de purificação $(2,99-3,31)$.

\section{Conclusão}

Levando em consideração os resultados da purificação parcial da exo-poligalacturonase (exo-PG), observou-se que as maiores recuperações da enzima foram obtidas em concentração de solvente de $3 \mathrm{~V}$ (três volumes) para etanol e $2 \mathrm{~V}$ (dois volumes) para a acetona com valores de $47,05 \%$ e $42,85 \%$, respectivamente. Para o sulfato de amônio a melhor recuperação, com $29,33 \%$, foi observada para a concentração de $20 \%$.

Os resultados obtidos são considerados promissores quando comparados com dados da literatura, demonstrando que podem ser recomendadas para o uso industrial, visto que os métodos se mostraram eficientes para a enzima estudada, além de serem técnicas de purificação simples, de baixo custo e pode possuir a mesma eficácia que algumas técnicas cromatográficas, ou em alguns casos, ser ainda mais eficiente que elas.

\section{Referências}

Abdulaal W.H. \& Almulaiky, Y.Q. (2020) Purification and Thermodynamic Characteristics of an Exo-Polygalacturonase from Trichoderma Pseudokoningii. J Chem Soc Paquistão. 42 (5). 767-775.

Ahmed, I.; Zia, M.A., Hussain, M.A., Akram, Z., Naveed, M.T. \& Nowrouzi, A. (2016). Bioprocessamento de cascas de resíduos cítricos para produção induzida de pectinase por Aspergillus niger; sua purificação e caracterização. J. Radiat. Res. Appl. Sci, 9, 148 - 154.

Amin, F., Arooj, T., Nazli, Zi., H., Bhatti, H.N. \& Bila, M. (2021). Produção de exo-poligalacturonase a partir de agro-resíduos por Penicillium fellutanum e visão sobre a clarificação termodinâmica, cinética e de suco de frutas. Biomass Conv. Bioref. https://link.springer.com/article/10.1007/s13399-021-01902-2

Biazus, J.P.M., Santana, J.C.C., Souza, R.R. \& Tambourgi, E.B. (2010) Purificação de amilases de malte de Zea mays. Ciênc. Tecnol. Aliment., 30(1), 218223.

Bom, E. P. S., Ferrara, M. A. \& Corvo, M. L. (2008) Enzimas em biotecnologia: Produção, Aplicações e Mercado. Interciênicas LTDA. UFRJ.

Bradford, M. M. (1976) A rapid and sensitive method for the quantification of microgram quantities for protein utilizing the principle of protein -dye binding. Analytical Biochemistry,72, 248-254.

Burgess, R. R. (2009) Protein precipitation techniques. Methods Enzymol. 463. 331-342.

Cortez, E. V. \& A. Pessoa Jr. (1999) Xylanase and b-xylosidase separation by fractional precipitation. Process Biochemistry, 35, $277-283$.

Damodaran, S., Parkin, K. L. \& Fennema, O. R. (2018) Química de alimento de Fennema. Artmed. (5).

Freire, D.M.G. Seleção de microrganismos lipolíticos e estudo da produção de lipase por Penicillium restrictum. (1996) Tese de Doutorado. Universidade Federal do Rio de Janeiro, RJ.

Gomes J., Zeni J., Cence K., Toniazzo G., Treichel H., Valduga E. (2010) Evaluation of production and characterization of poligalacturonase by Aspergillus niger ATCC9642. Food and Bioproducts Processing. 89. 281-287.

Gautam, A. K., Sharma, S., Avasthi, S. \& Bhadauria, R.. (2011). Diversity, pathogenicity and toxicology of A. niger: an important spoilage fungi. Research Journal of Microbiology. Enzyme and Microbial Technology, 6 (3), 270-280.

Huang, D., Song, Y., Liu, Y. \& Qin, Y. (2019). Uma nova cepa de Aspergillus tubingensis para a produção de pectinase de alta atividade. Braz J Microbiol, $50,53-65$. 
John, J., Surendranathan, K.K., Kaimal, M. L. S., Pattanathu K.S.M. \& Rahman, P. V.C. (2020). Advances in upstream and downstream strategies of pectinase bioprocessing: A review, International Journal of Biological Macromolecules, 162, 1086-1099.

Kanwar, S. S., Ghazi, I. A., Chimi, S. S., Joshi, G. K., Rao, G. V., Kaushal, R. K., Gupta, R. \& Punj, V. (2006) Purification and properties of a novel extracellular thermotolerant metallolipase of Bacillus coagulans MTCC-6375 isolate. Protein Expression and Purification, 46, 421-428.

Ktari, N., Khaled, H., Nasri, R., Jellouli, K. \& Ghorbel, Sofiane. (2012). Trypsin from zebra blenny (Salaria basilisca) viscera: Purification, characterisation and potential application as a detergent additive. Food Chemistry. 130. 467-474.

Miller, G.L. (1956) Use of dinitrosalicylic acid reagent for determination of reducing sugar. Analytical Biochemistry, 31, $426-428$.

Pagnonceli, J. Purificação, caracterização e aplicação de uma exo-poligalacturonase de Penicillium janthinellum VI2R3M. Mestrado em ciências Farmacêuticas. Universidade Estadual do Oeste do Paraná, Campus Cascavel. 2018.

Pereira, L.L.S., Santos, C.D., Pereira, C.A., Marques, T.R. \& Sátiro, L.C. (2010) Precipitação do inibidor de $\alpha$-amilase de feijão branco. Alimentos e Nutrição. Araraquara $21(1), 15-20$.

Prestes, O.D., Adaime, M.B. \& Zanella, R. (2011). QuEChERS: possibilidades e tendências no preparo de amostra para determinação multirresíduo de pesticidas em alimentos. Scientia Chromatographica, 3 (1), 51-64.

Purwanto, M. G. M. (2016) The role and efficiency of ammonium sulphate precipitation in purification process of papain crude extract. Procedia Chemistry, $56,3643-3650$

Razzaq, A., Shamsi, S., Ali, A., Ali, Q., Sajjad, M., Malik, A. \& Ashraf, M. (2019) Microbial Proteases Applications. Frontiers in Bioengineering and Biotechnology, 7, 1-20.

Muruci, L. M. N. (2012). Produção e caracterização de lipase de Aspergillus niger obtida por fermentação no estado sólido utilizando resíduos da agroindústria. Tese, Doutorado em Ciência e Tecnologia de Alimentos - Universidade Federal Rural do Rio De Janeiro, Seropédica.Universidade Federal Rural do Rio de Janeiro, Seropédica.

Nawaz, A., Sameer, M., Akram, F., Tahir S. F., Arshad, Y., Haq, I. U. \& Mukhtar, H. (2021). Visão cinética e termodinâmica de uma poligalacturonase: um biocatalisador para clarificação de sucos de frutas industriais. Revista Mexicana de Ingeniería Química. 20, 1029-1045.

Salehi, M., Aghamaali, M. R., Sajedi, R. H., Asghari, S. M. \& Jorjani, E. (2017) Purification and characterization of a milk-clotting aspartic protease from Withania coagulans fruit. International Journal of Biological Macromolecules, 98, 847-854.

Santos, C.W.V. (2020) Serino protease e inibidor de tripsina: purificação, caracterização e aplicação biotecnológica. Tese de Doutorado. Programa de pósgraduação em Química e Biotecnologia da Universidade Federal de Alagoas. Maceió-AL.

Santos, V. P. S., Mendonça, C., Pereira, P. R., Gutarra, M. L. E., Torres, A. G., Pereira, K. S. \& Salgado, A. M. (2014) Comparação de métodos de extração e caracterização da enzima tironase de Agaricus Bisporus. Congresso Brasileiro de Engenharia Química. Florianópolis-SC.

Santos Junior, A. G., Piraine, R. E. A., Cunha, R. C., Nizoli, L. Q., Andreotti, R, \& Leite, F. P. L. (2017) Avaliação de métodos para obtenção de proteínas recombinantes. Science and Animal Health. 5. 166-177.

Tacin, M. V., Massi, F. P., Fungaro, M. H., Teixeira, M. F., de Paula, A. V., \& de Carvalho Santos-Ebinuma, V. (2019). Biotechnological valorization of oils from agro-industrial wastes to produce lipase using Aspergillus sp. from Amazon. Biocatalysis and Agricultural Biotechnology. 19. 369-378.

Tackcı, H. A. M. \& Turkmen, F. U. (2016) Extracellular Pectinase Production and Purification from a Newly Isolated Bacillus subtilis Strain, International Journal of Food Properties, 19. 2443-2450.

Trentini, M. M. S. (2014) Purificação de pectinases produzidas por aspergillus niger ATCC 9642 em sistemas aquosos bifásicos e precipitação por solventes orgânicos. Tese de Doutorado. Universidade Regional Integrada do Alto Uruguai e das Missões- Campus Erechim.

Waglay, A., Karboune, S. \& Alli, I. (2014) Potato protein isolates: Recovery and characterization of their properties. Food Chemistry, 142 , 373-382.

Wingfield, P. T. (2001) Protein Precipitation Using Ammonium Sulfate. Current Protocols in Protein Science, 84, 1-10.

Yoshikawa, H., Hirano, A., Arakawa, T. \& Shiraki, K. (2012) Mechanistic insights into protein precipitation by alcohol. International Journal of Biological Macromolecules, 50, 865-871.

Zeni, J., Cence, K., Grando, C. E., Tiggermann, L., Colet, R., Lerin, L. A., Cansian, R. L., Toniazzo. G., Oliveira, D. \& Valduga, E. (2011) Seleção de microrganismos produtores de pectinase com atividade de poligalacturonase. Appl Biochem Biotechnol, 163, 383-392. 